\title{
OS EFEITOS DA CLÁUSULA DE VOTAÇÃO NOMINAL MÍNIMA NO SISTEMA ELEITORAL BRASILEIRO
}

\author{
Effects of the Minimum Nominal Voting Clause in the Brarilian Electoral System
}

Henrique Kurscheidt

Resumo: O presente artigo tem por objetivo apresentar o sistema proporcional adotado pelo direito eleitoral brasileiro para preenchimento das vagas nas eleições de Deputados Federais, Deputados Distritais e Estaduais e de Vereadores, os objetivos e razão de ser de tal sistema e ponderar o efeitos trazidos em tal sistemática pela cláusula de votação nominal mínima, instituída pela Minirreforma Eleitoral de 2015 (Lei 13.165/2015), que deu nova redação ao art. 108 da Lei 4.737/1965 (Código Eleitoral), para vedar a eleição de candidatos, nas eleições proporcionais, cuja votação não alcance 10\% do quociente eleitoral e que foi recentemente declarada constitucional pelo Supremo Tribunal Federal (ADI 5920).

Palavras-chave: Direito eleitoral. Sistemas eleitorais. Sistema proporcional. Quocientes eleitoral e partidário. Cláusula de votação nominal mínima.

\begin{abstract}
This article presents the proportional system adopted in Brazil to elect deputies at the federal and state levels, deputies of the country's federal district, and city councilors. The study explores the objectives and the reason for the system and discusses how it has been affected by the minimum nominal voting clause, instituted by the 2015 Electoral Reformation (Law 13165/2015). The clause was recently declared constitutional by the Supreme Federal Court (ADI 5920) and changed art. 108 of Law 4737/1965 (Electoral Code), banning the election of candidates, in proportional elections, whose voting does not reach $10 \%$ of the electoral quotient.
\end{abstract}

Keywords: Electoral law. Electoral systems. Proportional system. Electoral and party quotient. Minimum nominal voting clause.

Artigo recebido em 3 abr. 2020 e aprovado em 21 out. 2020. 


\section{Introdução}

A fórmula proporcional, utilizada no direito eleitoral brasileiro para definição dos candidatos vitoriosos nas eleições de Deputados Federais, Estaduais e Distritais e dos Vereadores, é alvo de frequentes críticas por ser pouco compreendida pelo eleitorado e por não raro levar a resultados que geram perplexidade por, aparentemente, distorcerem a vontade popular manifestada nas urnas, como, por exemplo, quando o voto atribuído a determinado candidato acaba servindo para eleger outro, por vezes desconhecido ou representante de corrente ideológica diversa daquela que o eleitor pretendia prestigiar com seu voto, ou, ainda, quando candidatos com baixíssima votação acabam sendo eleitos em detrimento de outros com votações mais expressivas.

O fenômeno dos "puxadores de votos", como são conhecidos os candidatos que, por contarem com grande popularidade, acabam angariando votos suficientes para preencher por várias vezes o quociente eleitoral e conquistar diversos mandatos para sua agremiação, é um dos mais notórios efeitos nefastos da fórmula proporcional, por permitir a eleição de candidatos com votação inexpressiva e dotados de pouca representatividade, os chamados "caroneiros".

Para restringir os efeitos da presença dos "puxadores de voto" no resultado das eleições, o legislador ordinário, por meio da minirreforma eleitoral de 2015 (Lei 13.165/2015), alterou a fórmula proporcional e instituiu cláusula de votação nominal mínima, passando a vedar a eleição de candidatos, nas eleições proporcionais, cuja votação não alcance 10\% do quociente eleitoral.

A mudança legislativa que instituiu a exigência de votação nominal mínima foi alvo de Ação Direta de Inconstitucionalidade perante o Supremo Tribunal Federal (ADI 5920), que, em recente decisão, declarou a constitucionalidade da cláusula de votação nominal mínima.

Assim, dada a recente declaração de constitucionalidade da sistemática trazida pela minirreforma eleitoral de 2015, o presente estudo tem por objetivo analisar os efeitos de tal modificação no sistema proporcional adotado pelo direito eleitoral brasileiro.

Em tal análise, buscou-se realizar ampla revisão bibliográfica acerca do objeto de estudo, orientado pelo método indutivo e estruturado em quatro capítulos, iniciando-se, no primeiro capítulo, com uma apresentação 
dos sistemas eleitorais, com ênfase no sistema proporcional; no segundo capítulo são apresentadas as críticas direcionadas ao sistema proporcional brasileiro e as mudanças instituídas pela minirreforma eleitoral de 2015, dentre elas a cláusula de votação nominal mínima; no terceiro capítulo, são apresentados os fundamentos da ADI 5920 e dos principais votos proferidos no julgamento que resultou na declaração de constitucionalidade da exigência de votação nominal mínima e, no quarto e último, os fundamentos do julgado são analisados e sopesadas suas consequências e possíveis soluções alternativas. Por fim, conclui-se que, embora não se possa considerar inconstitucional a exigência de votação nominal mínima, tal modificação, instituída com o objetivo pontual de corrigir a distorção causada pelos "puxadores de voto", traz consigo outros efeitos nefastos e potencialmente prejudiciais à adequada representação política das diferentes correntes ideológicas e posições partidárias que vigora em nossa democracia, a evidenciar a necessidade de reformas e aprimoramentos mais amplos em nosso sistema eleitoral, sugerindo-se adoção do sistema distrital misto, como possível solução para aumentar a representatividade democrática dos parlamentos, além de possivelmente baratear as eleições e facilitar a governabilidade.

\section{Sistemas eleitorais e o sistema proporcional}

O procedimento para contabilização de votos e definição dos candidatos eleitos é determinado pelo sistema eleitoral, que constitui, segundo Nicolau $(2007,293)$, o "conjunto de regras que define como (...) os eleitores podem fazer as suas escolhas e como os votos são somados para serem transformados em mandatos (cadeiras no legislativo ou chefia do Executivo)", ou, no dizer de Norberto Bobbio, o conjunto de "procedimentos institucionalizados para atribuição de encargos por parte dos membros de uma organização ou de alguns deles” (BOBBIO, 1991, 1174).

Sobre o tema, Luís Virgílio Afonso da Silva adverte que:

(...) quanto maior for a manipulação que um sistema eleitoral produz, menor será a efetiva influência que os cidadãos poderão exercer na composição do poder político e, como consequência, menor será o efeito legitimador produzido pelas eleições (SILVA, 1999, 39).

A legislação brasileira prevê a adoção de dois sistemas eleitorais distintos, a depender da natureza do cargo eletivo em disputa: o majoritário, 
utilizado na eleição dos chefes do Poder Executivo e Senadores (conforme arts. 28, 29, II, 32, \ $2^{\circ}, 46$ e 77, \ $2^{\circ}$, da CF/88), e o proporcional de lista aberta, utilizado nas eleições de Deputados Federais, Deputados Distritais e Estaduais e Vereadores (conforme arts. 27, \ 1ㅇ, 29, IV, 32, \ 3o e 45 da CF/88 e art. 83 do Código Eleitoral).

Ao comparar e ressaltar as características de cada um dos sistemas eleitorais adotados no direito eleitoral brasileiro, o ministro Carlos Ayres Brito, em didático voto proferido quando do julgamento pelo Supremo Tribunal Federal, do Mandado de Segurança n 26.602/DF, em que se discutia se o mandato político pertence ao candidato eleito ou ao seu partido, bem pontuou as características centrais de cada um dos sistemas:

Pelo princípio majoritário de eleição, próprio das candidaturas a cargo de senador da República, a majoritariedade mesma (a significar vitória eleitoral pela obtenção da maioria nominal ou unipessoal de votos) tem que ser alcançada pelos candidatos. Uns em confronto com os outros. Candidatos versus candidatos. Já pelo sistema proporcional de eleição, essa majoritariedade há de ser alcançada pelos partidos políticos e suas eventuais coligações. Uns em oposição aos outros. Partido versus partido, coligação versus coligação. Do que se percebe, instantaneamente, que pelo primeiro sistema (o majoritário) há um componente bem maior de individualidade. De prestígio pessoal de cada um dos contedores. Cada qual a se confrontar, pessoalmente, com seus adversários. Sem que se exija das respectivas agremiações partidárias (isolada ou aliançadamente) nenhum patamar de votos mínimos. Nenhuma cláusula quantitativa de barreira. Tudo se resolve pelo escore eleitoral do jogo entre individualizados contedores, que não podem se beneficiar do bom desemprenho senão de si mesmos. Logo, sem que se possa falar nem de puxadores de votos nem de caroneiros. Ainda que se trate de eleição para preenchimento de duas vagas em cada Estado e no Distrito Federal.

Ora bem, tudo isso é o contrário do que se dá na órbita do sistema proporcional. Aqui, a majoritariedade deixa de ser imediatamente individual para ser coletiva. A performance eleitoral do conjunto dos agremiados é o que mais conta. Exige-se desse conjunto um patamar mínimo de votos, e não dos candidatos de per se. Logo, a exigência da obtenção de maioria de votos (majoritariedade) não se encarna senão em cada partido e em cada eventual coligação ${ }^{1}$.

\footnotetext{
${ }^{1}$ Disponível em: <http://www.stf.jus.br/arquivo/cms/noticiaNoticiaStf/anexo/ms26602CB.pdf>.
} 
O traço marcante do sistema eleitoral majoritário é a obtenção de resultado que reflete a vontade da maioria dos eleitores (notadamente quanto utilizado o sistema de dois turnos), identificada sobretudo com a pessoa do candidato. O sistema proporcional, que é objeto de análise no presente estudo, visa propiciar a adequada representação política das diferentes correntes de pensamento existentes em determinada sociedade, ainda que de caráter minoritário e que, ao menos no plano ideal, são representadas pelos diversos partidos políticos.

Ao discorrer acerca das finalidades e objetivos do sistema proporcional, Jairo Nicolau ensina que:

a fórmula proporcional tem duas preocupações fundamentais: assegurar que a diversidade de opiniões de uma sociedade esteja refletida no Legislativo e garantir uma correspondência entre os votos recebidos pelos partidos e sua representação. A principal virtude da representação proporcional, segundo seus defensores, estaria em sua capacidade de espelhar no legislativo todas as preferências e opiniões relevantes existentes na sociedade" (NICOLAU, 2004, 37).

No mesmo sentido é o escólio de Norberto Bobbio:

O princípio proporcional acompanha a moderna democracia de massas e a ampliação do sufrágio universal. Partindo da consideração de que, numa assembleia representativa, deve criar-se espaço para todas as necessidades, todos os interesses e todas as ideias que animam um organismo social, o princípio proporcional procura estabelecer a perfeita igualdade de voto e dar a todos os eleitores o mesmo peso, prescindindo de preferência manifesta (BOBBIO, 1991, 1175).

No sistema proporcional de lista aberta, adotado pelo direito eleitoral brasileiro, os partidos políticos possuem papel destacado, sendo a eles inicialmente destinados os mandatos, que são posteriormente distribuídos entre seus candidatos de acordo com o número de votos obtido por cada um.

O número de cadeiras a ser atribuído a cada partido político é definido por meio da aplicação dos chamados quociente eleitoral e partidário. O quociente eleitoral, nos termos do art. 106 do Código Eleitoral, é obtido pelo número total dos votos válidos dividido pelo número de vagas em 
disputa em cada circunscrição eleitoral, desprezando-se a fração se igual ou inferior a meio e equivalendo-a a um, se superior.

Em seguida, é obtido o quociente partidário, pela divisão do número de votos obtidos por determinado partido político (votos na legenda e nominais) pelo quociente eleitoral, desconsiderando-se a fração. O resultado dessa divisão, que indica o quociente partidário, equivale ao número de cadeiras a ser inicialmente atribuída a cada partido político, restando as chamadas "sobras" (lugares não preenchidos com a aplicação dos quocientes partidários), que são distribuídas seguindo a sistemática prevista no art. 109 do Código Eleitoral, por meio da divisão do número de votos válidos de cada partido pelo número de lugares por ele obtido mais um, com a atribuição sucessiva das vagas remanescentes àquele que apresentar a maior média.

Finalmente, após a definição do número de cadeiras obtido por cada partido político, as vagas conquistadas são atribuídas a seus respectivos candidatos de acordo com o número de votos nominais obtido por cada um deles em lista aberta.

\section{Das críticas e alterações no sistema proporcional}

A fórmula proporcional, em razão de sua relativa complexidade e por ser pouco compreendida por parte do eleitorado, conduz, com alguma frequência, a resultados que geram perplexidade e críticas, como, por exemplo, nas hipóteses em que o voto atribuído a um representante de determinada corrente de pensamento ou posição política, acaba servindo para eleger outro candidato, defensor de orientação ideológica oposta, ou na hipótese dos chamados "puxadores de voto", que, por contarem com grande popularidade e projeção, acabam angariando votações expressivas e que sozinhas garantem diversas das vagas em disputa, levando, por vezes, a eleição de candidatos sem nenhuma representatividade ou experiência política, eleitos apenas por integrarem o partido ou coligação do "puxador de voto".

As eleições dos deputados federais Enéas Carneiro e, mais recentemente, Tiririca, são exemplos notórios da segunda hipótese, tendo o primeiro obtido votação de mais de 1,5 milhão de votos nas eleições gerais de 2002, que resultou na obtenção de seis cadeiras na Câmara dos Deputados 
para seu partido político ${ }^{2}$ e na eleição de um deputado federal que havia obtido apenas 275 votos; em um pleito no qual 17 candidatos com mais de 70 mil votos deixaram de ser eleitos. A história registra exemplo ainda mais extremo, ocorrido na eleição de 1945, na qual um candidato que não registrou nenhum voto nominal (Hermelindo de Gusmão Castelo Branco Filho) acabou sendo eleito deputado federal, pelo então Território do Acre, em razão dos votos obtidos por outro candidato de seu partido político.

Visando corrigir tais distorções, são frequentes as propostas de modificação e aprimoramento do sistema eleitoral pátrio, notadamente no que tange à fórmula proporcional, alvo preferencial dos críticos da atual sistemática, que atribuem a ela a atual crise de representação política.

Nesse sentido, foram aprovadas, nos últimos anos, importantes modificações legislativas, que alteraram substancialmente o sistema de definição dos candidatos eleitos pelo sistema proporcional, dentre as quais se destaca a minirreforma eleitoral de 2015 (Lei 13.165/2015).

\subsection{Da minirreforma eleitoral de 2015}

A Lei 13.165/2015, promulgada com o declarado intuído de "reduzir os custos das campanhas eleitorais, simplificar a administração dos partidos políticos e incentivar a participação feminina", alterou em diversos pontos a sistemática eleitoral, tendo, dentro outras modificações, alterado o quórum necessário para julgamento das ações que importem cassação de registro, anulação geral de eleições ou perda de diplomas pelos Tribunais Regionais Eleitorais (art. 28, $\iint 4^{\circ}$ e 5 , da CE); as datas para requerimento e julgamento do registro de candidato a cargo eletivo (art. 93, caput e $\mathbb{1} 1^{\circ}$, do CE) e o prazo para realização das convenções partidárias para a escolha dos candidatos (art. 93, \2 , do CE); instituída a necessidade de realização de novas eleições após o trânsito em julgado de decisão da Justiça Eleitoral que resulte no indeferimento do registro, cassação do diploma ou perda do mandato de candidato eleito em pleito majoritário (art. 224, \ 3을 do CE); ampliadas as possibilidades de voto em trânsito (art. 233-A do CE) e restringido o período de propaganda eleitoral (art. 240 do CE).

\footnotetext{
${ }^{2}$ Amauri Roblego Gasques com 18.344 votos, Irapuan Teixeira com 668 votos, Elimar Máximo Damasceno com 483 votos, Ildeu Alves de Araújo com 382 votos e Vanderlei de Assis de Souza com 275 votos. Disponível em: <https://www1.folha.uol.com.br/fsp/ brasil/fc0810200255.htm>.
} 
No ponto que interessa ao presente estudo, a minirreforma eleitoral modificou o art. 108 do Código Eleitoral, que passou a contar com a seguinte redação:

Art. 108. Estarão eleitos, entre os candidatos registrados por um partido ou coligação que tenham obtido votos em número igual ou superior a 10\% (dez por cento) do quociente eleitoral, tantos quantos o respectivo quociente partidário indicar, na ordem da votação nominal que cada um tenha recebido.

Nos termos da nova redação do dispositivo legal transcrito acima, a obtenção de mandato eletivo em eleição proporcional deixou de depender apenas da conquista de posição em lista dentro do número de vagas obtido pela agremiação, passando a exigir, também, a obtenção de votação nominal em número igual ou superior a 10\% do quociente eleitoral.

Tal modificação foi realizada com o claro intuito de diminuir os efeitos da presença dos "puxadores de voto" na lista de determinado partido político e dificultar a eleição de candidatos com baixa representatividade e projeção política.

Tendo sido publicada em 29/09/2015, a Lei 13.165/2015 foi aplicada nas eleições gerais de 2018, tendo se mostrado eficaz para reduzir os efeitos da presença dos "puxadores de voto" e restringir as eleições dos chamados "caroneiros". A título de exemplo, é possível citar a situação do Partido Social Liberal - PSL de São Paulo, que, por força da expressiva votação obtida pelo deputado federal Eduardo Bolsonaro, que angariou 1,84 milhão de votos, possuía votos em número suficiente para eleger 17 deputados, mas, por possuir apenas 10 candidatos com votação igual ou superior ao quociente eleitoral (que correspondia a aproximadamente $30 \mathrm{mil}$ votos), acabou perdendo 7 destas vagas ${ }^{3}$, que foram distribuídas a outras agremiações.

\section{A Ação Direta de Inconstitucionalidade 5920}

Em que pese o êxito obtido pela novel legislação em restringir a eleição de candidatos de baixa representatividade na esteira dos "puxadores de voto", parte da doutrina externou preocupação com os efeitos da ado-

\footnotetext{
${ }^{3}$ Disponível em: <https://www.camara.leg.br/noticias/545969-mudanca-no-quociente-
} -eleitoral-enfraqueceu- puxadores-de-votos $/>$. 
ção de tal sistemática em nossa dinâmica eleitoral, principalmente em razão do possível enfraquecimento do já combalido sistema partidário brasileiro, com a diminuição do papel das legendas políticas, enquanto representantes das diversas correntes ideológicas em vigor, em função da necessidade de fomento do voto nominal, em detrimento do voto na legenda, para que seja atingida a votação mínima por número suficiente de candidatos para aproveitamento integral das cadeiras obtidas pela agremiação.

Nesse sentido:

Com o advento da Lei oํ 13.165/2015, que passou a exigir cláusula de votação nominal mínima (10\% do quociente eleitoral), pode-se gerar uma situação de extrema relevância jurídica, quando, no limite exemplificativo, o partido ou coligação que tenha obtido mais votos não preencha sequer uma vaga, considerando que nenhum candidato obteve a referida cláusula (grande pulverização de votos entre os candidatos do partido ou da coligação ou número espetacular de votos de legenda), ou, ainda como exemplo, quando o partido ou coligação mais sufragada nas urnas alcance um número bem menor de lugares comparado com outros concorrentes que obtiveram votação inferior. É dizer, o modelo atual pode fomentar, na própria agremiação partidária, a necessidade de difundir o voto nominal, o voto em determinado candidato, e não na própria legenda, o que pode enfraquecer ainda mais o próprio sistema partidário brasileiro (MENDES, 2016, 27).

Sob outro aspecto, outros autores apontam que a nova legislação subverte o próprio sistema de representação proporcional, adotado pela Constituição Federal para eleição de deputados federais, estaduais e distritais ${ }^{4}$, ao retirar, no todo ou em parte, as vagas conquistadas pelos partidos políticos em razão da votação individualmente obtida por seus candidatos:

(...) o sistema proporcional citado no texto constitucional se refere ao gênero, cuja finalidade é garantir uma proporção matemática na relação de quantidade de votos e cadeiras, assim como equilibrar a disputa do pleito, dando chances maiores de a minoria ter representação no poder.

Por sua vez, o Código Eleitoral adota como espécie do gênero o sistema de listas, onde o protagonismo da disputa pelo poder consiste

\footnotetext{
${ }^{4}$ A aplicação da fórmula proporcional nas eleições de vereadores não está prevista no texto constitucional e sim no art. 84 do CE.
} 
nos grupos - nos partidos. Aqui a essência é dizer quantas cadeiras cada partido conquistou na disputa do pleito, independentemente da fórmula matemática escolhida.

Por fim, a referida norma legal complementa a espécie sistema de lista com a subespécie lista aberta. Qualquer que fosse a subespécie preferida, a sua base teórica é somente para indicar quem serão os representantes dos partidos que conquistaram as cadeiras na disputa eleitoral. A de lista aberta diz que os representantes eleitos serão os mais preferidos dos apoiadores do partido, ou seja, aquele que obteve as maiores votações.

(...)

Com efeito, a exigência de votação mínima para eleger os representantes dos partidos é contraditória com a própria ideia do sistema de listas, bem como com o ordenamento jurídico.

Como visto, na espécie sistema de listas a disputa ocorre somente entre os partidos e coligações. Logo, a cadeira conquistada pertencerá ao partido e não ao candidato, independentemente de sua votação. (...)

Ora, se a cadeira é conquistada pela espécie de sistema proporcional adotada, não há como uma norma regulamentar de subespécie retirar esse direito adquirido pela espécie. Cabe relembrar que a subespécie escolhida pelo nosso ordenamento é a lista aberta, onde o eleitor escolhe o melhor candidato para representar o partido. A subespécie serve somente para indicar quem representa o partido, não para limitar o acesso e retirar vagas conquistadas. Ademais, aplica-se nessa ideia organizacional do sistema proporcional (gênero, espécie e subespécie) a supracitada lição de Bobbio (1999, p. 53-54), em que há uma hierarquia na qual as normas inferiores (subespécie) devem respeitar as normas superiores em questões formais e materiais, uma vez que somente têm validade por causa dessas normas. Além disso, devido ao fato de o sistema eleitoral proporcional de listas ser positivado e dele decorrer a disputa entre partidos, por força imperativa da lei aos eleitores, há a presunção de que o povo vota em partido, não nas pessoas dos candidatos, visto que, no referido sistema, estes não disputam cadeiras, apenas a representação do partido com seus colegas de associação. De mais a mais, tal norma pode levar ao absurdo de um partido conseguir conquistar $n$ vagas e não eleger ninguém, bem como, de fato, desconsiderar votos válidos e prejudicar os partidos que tenham alcançado quociente eleitoral e partidário, mas não conseguir a exigência da quantidade mínima de votos nominal (VILELA JR, 2016, 138-141). 
$\mathrm{Na}$ esteira dessas ponderações doutrinárias, a constitucionalidade do limite mínimo de votação individual de 10\% do quociente eleitoral para preenchimento das vagas nas eleições proporcionais, instituída pela Lei 13.165/2015, foi questionada pelo Partido Ecológico Nacional, que ajuizou Ação Direta de Inconstitucionalidade (ADI 5920) perante o Supremo Tribunal Federal, sustentando, em síntese, que os dispositivos impugnados trazem distorção ao sistema constitucional de representação proporcional, uma vez que possibilitam que um partido ou coligação que possua candidatos de expressão mediana, mesmo que ultrapasse em muito o quociente eleitoral, não obtenha nenhuma vaga, o que, segundo a ADI, traz grave distorção à fórmula proporcional, que visa à união de forças e salvaguarda do direito de minorias no cenário político, em afronta aos arts. 1ำ parágrafo único, e 45 , caput e $\int 1$, , parte inicial, da $\mathrm{CF} / 88$.

A relatoria da ADI 5920 foi atribuída ao ministro Luiz Fux e, em sessão extraordinária realizada no dia 04 de março de 2020, o Supremo Tribunal Federal julgou improcedente a ação, em votação unânime, declarando a constitucionalidade do art. $4^{\circ}$ da Lei 13.165/15, que alterou a redação do art. 108 do Código Eleitoral para instituir a cláusula de votação nominal mínima.

Em seu voto, o ministro relator ressaltou que o eleitor brasileiro em regra vota na pessoa do candidato e que, em todas as democracias do mundo, o que se valoriza é a manifestação de vontade intuito personae do eleitor. Citou dados obtidos na última eleição que demonstram que a aplicação da cláusula de desempenho mínimo impediu a eleição de apenas oito candidatos em todo país, sete deles no estado de São Paulo e um no Rio Grande de Sul; que os oito candidatos impedidos por força da atual redação do art. 108 do CE obtiveram, somados, 171 mil votos e que os candidatos eleitos, que foram beneficiados pela reforma eleitoral, somaram seis vezes mais, totalizando 609 mil votos. Sustentou que não há que se falar em vulneração ao sistema proporcional, pois a minirreforma eleitoral não alterou a regra de quociente eleitoral e quociente partidário. Ressaltou que a Constituição Federal, ao tratar do tema, não desceu a minúcias, tendo adotado o sistema proporcional, mas deixando por conta do legislador ordinário sua regulamentação, que fez uma escolha razoável e que, em regra, deve-se deferência à escolha legislativa.

O ministro Alexandre de Moraes acrescentou que a opção pelo sistema proporcional é definida na Constituição Federal, mas que é a legislação infraconstitucional que estabelece qual sistema proporcional será adotado. Observou que nosso país adotou tradicionalmente algumas ca- 
racterísticas que geraram distorções, levando os candidatos de um mesmo partido a disputarem votos entre si e não com os candidatos de outros partidos, o que foi agravado pela possibilidade de coligações em eleições proporcionais, o que acabava levando a um verdadeiro estelionato eleitoral, com a eleição de candidatos de ideologias diversas daqueles que receberam os votos. Reputou que o legislador acertou ao instituir a cláusula de votação nominal mínima, mas, ainda que não tivesse acertado, não seria o caso de inconstitucionalidade. Concluiu afirmando que a cláusula gera maior legitimidade para aqueles que foram eleitos e reforça os partidos políticos.

O ministro Ricardo Lewandovski ressaltou que essa primeira medida, trazida pela minirreforma eleitoral de 2015, é um pequeno passo no sentido de resolver as distorções que ainda persistem no sistema eleitoral brasileiro e visa encontrar um equilíbrio entre prestigiar o partido de um lado e de outro lado o próprio eleitor, tendo destacado, também, que, consoante dados estatísticos apresentados pela Procuradoria-Geral da República, se a nova regra estivesse em vigor nas eleições de 2012, seu impacto teria sido ínfimo, impedindo a eleição de apenas 18 candidatos em todo Brasil.

Finalmente, o ministro Luís Roberto Barroso propôs uma reflexão sobre o sistema proporcional em lista aberta adotado no Brasil, ressaltando que, nas últimas eleições, apenas $5 \%$ dos deputados federais foram eleitos com votação própria e 95\% dos eleitos obtiveram o mandato graças a transferência de votos proporcionada pela fórmula proporcional. Afirmou que, por conta dessa sistemática, a discussão eleitoral não pode ser programática porque os candidatos concorrem principalmente com os demais integrantes de seu próprio partido político. Concluiu afirmando que o sistema atual é caro, causa baixa representatividade e dificulta a governabilidade e que a exigência de votação mínima trazida pela minirreforma eleitoral de 2015 nada tem de inconstitucional e constitui medida paliativa para minimizar um dos efeitos nefastos do sistema proporcional em lista aberta, que é o dos "puxadores de voto", que, em última análise, é uma fraude à vontade do eleitor, porque permite a eleição de candidatos que não têm votação, em detrimento de pessoas representativas. Mencionou, como possível solução desse quadro, a adoção do sistema distrital misto, na forma da proposta ${ }^{5}$ elaborada pelo Grupo de Trabalho instituído pelo Tribunal Superior Eleitoral.

\footnotetext{
5 Disponível em: <http://www.tse.jus.br/imprensa/noticias-tse/arquivos/reforma-do-sistema-eleitoral/rybena_pdf?file=http://www.tse.jus.br/imprensa/noticias-tse/arquivos/reforma-do-sistema-eleitoral /at_download/file>.
} 
O julgado foi assim ementado:

DIREITO CONSTITUCIONAL E ELEITORAL. AÇÃO DIRETA DE INCONSTITUCIONALIDADE. ART. 4 DA LEI FEDERAL 13.165/2015, NA PARTE EM QUE DEU NOVA REDAÇÃO AO ART. 108 DO CÓDIGO ELEITORAL (LEI 4.737/65). REPRESENTAÇÃO PROPORCIONAL. CLÁUSULA DE DESEMPENHO INDIVIDUAL DE CANDIDATO PARA ELEIÇÃO. 10\% DO QUOCIENTE ELEITORAL. INEXISTÊNCIA DE OFENSA AO PRINCÍPIO DEMOCRÁTICO OU AO SISTEMA PROPORCIONAL. ESPAÇO DE CONFORMAÇÃO DAS REGRAS DO SISTEMA CONFERIDO AO LEGISLADOR PELA CONSTITUIÇÃO. VALORIZAÇÃO DO VOTO NOMINAL CONDIZENTE COM O SISTEMA DE LISTAS ABERTAS E COM O COMPORTAMENTO DO ELEITOR BRASILEIRO. CONSTITUCIONALIDADE. IMPROCEDÊNCIA DA AÇÃO. 1. A cláusula de desempenho individual de $10 \%$ do quociente eleitoral para a eleição não viola o princípio democrático ou o sistema proporcional, consistindo, antes, em valorização da representatividade e do voto nominal, em consonância com o sistema de listas abertas e com o comportamento cultural do eleitor brasileiro. 2. O sistema proporcional impõe regras que devem observar as particularidades da realidade eleitoral do País, considerando aspectos culturais e fáticos, pois na experiência comparada não se percebem modelos perfeitos e pré-determinados. 3. O sistema eleitoral proporcional para a eleição de Deputados Federais, prescrito na Constituição Federal, submete suas minúcias ao legislador ordinário para a conformação da matéria. 4. Ação direta de inconstitucionalidade conhecida e julgados improcedentes os pedidos, para declarar a constitucionalidade do art. 4 da Lei Federal 13.165/2015, na parte em que deu nova redação ao artigo 108 da Lei Federal 4.737/1965 (Código Eleitoral). (ADI 5920, Relator(a): LUIZ FUX, Tribunal Pleno, julgado em 04/03/2020, PROCESSO ELETRÔNICO DJe-169 DIVULG 0307-2020 PUBLIC 06-07-2020).

\section{Análise crítica dos fundamentos da decisão proferida na ADI 5920 e possíveis consequências}

Ainda que a discussão acerca da constitucionalidade da cláusula de votação nominal mínima tenha sido superada pela decisão tomada pelo ple- 
nário do Supremo Tribunal Federal quando do julgamento da ADI 5920, alguns dos fundamentos adotados no julgado são passíveis de contraposição.

Em primeiro lugar, é de se ressaltar que a perplexidade causada pela potencial transferência de votos obtidos pelo "puxador de votos" para candidatos identificados com corrente ideológica diversa - mencionada em diversos dos votos como uma das razões pelas quais a cláusula de votação nominal mínima seria uma medida positiva - havia sido definitivamente solucionada, em momento anterior ao julgamento, pela supressão da possibilidade de coligações em pleitos proporcionais pela Emenda Constitucional $\mathrm{n}^{\mathrm{9}}$ 97/2017.

Com a supressão das coligações nas eleições proporcionais, a transferência de votos somente poderá ocorrer entre candidatos integrantes do mesmo partido político e que presumivelmente são partidários de ideias e propostas semelhantes.

Nesse contexto, a exigência de votação nominal mínima, além de desnecessária para solução desse problema específico (transferência de votos para partidário de corrente ideológica diversa), pode constituir um retrocesso no seu enfrentamento. Isso porque, pode propiciar a permanência dessa espécie de distorção em nosso sistema eleitoral, ao permitir que a corrente ideológica mais votada, representada por determinado partido político, nem sempre ocupe a maior parte das vagas em disputa, que podem acabar sendo atribuídas a partido político adepto de corrente ideológica contrária, a exemplo do que ocorreu com o Partido Social Liberal - PSL nas eleições de 2018, que, embora tenha angariado o maior número de votos, não obteve a maior bancada no parlamento.

Além disso, a instituição de votação mínima para obtenção do mandato eletivo, posto que certamente contribua para dificultar a eleição de candidatos de pouca expressão e experiência política, pode, em contrapartida, causar efeito ainda mais nefasto, consistente na sub-representação política dos eleitores que destinem seu voto a candidato que obtenha votação individual superior ao quociente eleitoral e integre partido político em que nenhum outro integrante da lista atinja a votação individual mínima. Caso tal situação ocorra com um dos chamados "puxadores de voto", essa sub-representatividade política pode atingir parcela considerável do eleitorado, em prejuízo da própria legitimidade democrática do resultado das eleições. 
Apenas para citar um exemplo, caso a exigência de votação nominal mínima estivesse em vigor nas eleições gerais de 2002, o deputado federal Enéas Carneiro, a despeito de ter obtido, naquele pleito, votação superior a 1.5 milhão de votos, equivalente a mais de 5 vezes o quociente eleitoral (que foi de 280.298 votos $^{6}$ ), teria obtido apenas o seu próprio mandato, por não contar com companheiro de agremiação com votação superior a $10 \%$ do quociente eleitoral, o que tornaria sem qualquer efeito os votos que excediam o quociente eleitoral, ou seja, nessa hipótese, mais de 1,3 milhão de eleitores, a despeito de terem exercido seu direito ao voto, não seriam adequadamente representados no parlamento.

A mesma distorção pode ocorrer em relação aos votos de legenda, que, com a nova sistemática, passam a possuir menor valor do que os votos nominais, por não contribuírem para o alcance da votação nominal mínima. Embora essa espécie de voto seja tradicionalmente adotada por parcela reduzida do eleitorado brasileiro (aproximadamente 6,58\% dos eleitores optaram pelo voto de legenda nas eleições de $2018^{7}$ ), inexiste justificativa para se atribuir menor valor ao voto dos eleitores que realizam tal opção, por se identificarem com a linha ideológica defendida por determinado partido político e não com determinado candidato.

Assim, por se tratar de medida que desestimula o voto de legenda, não se pode dizer que a cláusula de votação nominal mínima reforce a importância dos partidos políticos ou sua representatividade. Pelo contrário, reduz a relevância das agremiações partidárias como representantes de determinadas correntes de pensamento e reforça o caráter pessoal nas eleições proporcionais, aproximando-as do sistema majoritário.

Igualmente, é de se destacar que as duas principais distorções apontadas pelo voto do ministro Luís Roberto Barroso não serão solucionadas e, na realidade, poderão ser agravadas pela exigência de votação nominal mínima.

Em seu voto, o ministro Barroso destacou que, nas últimas eleições, apenas $5 \%$ dos deputados federais foram eleitos com votação própria e $95 \%$ dos eleitos obtiveram o mandato graças à transferência de votos proporcionada pela fórmula proporcional e que, por conta dessa sistemática, a discussão eleitoral não pode ser programática porque os candidatos concorrem principalmente com os demais integrantes de seu próprio partido político.

${ }_{6}^{6}$ Disponível em: <http://www.tse.jus.br/hotsites/catalogo-publicacoes/pdf/relatorio_ eleicoes/relatorio.pdf $>$. p. 188.

${ }^{7}$ Disponível em: <http://divulga.tse.jus.br/oficial/index.html>.

Resenha Eleitoral (Florianópolis), v. 24, n. 1, p. 129-148, 2020 
Contudo, a transferência de votos, que é inerente ao sistema proporcional, continuará a ocorrer, a despeito da exigência de votação individual mínima, com o agravante de que as vagas não aproveitadas pela ausência de candidato com votação superior ao percentual mínimo serão transferidas para candidato de partido político diverso, dissociando a representação democrática no parlamento da vontade popular manifestada pelo sufrágio.

Da mesma forma, a concorrência interna nos partidos políticos será ainda mais acirrada, em vista da necessidade de preenchimento da votação nominal mínima, reduzindo-se os estímulos à discussão eleitoral programática, notadamente pela redução do valor do voto de legenda. Tais circunstâncias, ao invés de facilitar, poderão tornar ainda mais difícil a formação de maiorias e a governabilidade, por diluir as vagas do parlamento entre um maior número de partidos políticos.

Por tudo isso, é possível concluir que a exigência de votação individual mínima no pleito proporcional aumenta a complexidade de um sistema que já é pouco compreendido pelo eleitor e descaracteriza o sistema proporcional adotado no Brasil, aproximando-o do sistema majoritário.

Esse cenário descortina a necessidade de modificação mais ampla no sistema eleitoral a fim de garantir a igualdade e direito de voto de todos os eleitores. Sensível a essa realidade, o TSE instituiu, por meio da Portaria 114/2019, Grupo de Trabalho, coordenado pelo ministro Barroso, visando à elaboração de propostas de reforma do sistema eleitoral e da legislação eleitoral. Os estudos do grupo de trabalho resultaram em relatório que propõe a adoção de um sistema distrital misto nas cidades com mais de 200 mil habitantes, como possível solução para aumentar a representatividade democrática dos parlamentos, além de, provavelmente, baratear as eleições e facilitar a governabilidade.

A proposta foi apresentada nos seguintes termos:

Como alternativa ao sistema atual, defende-se a adoção do sistema eleitoral distrital misto, que conjuga os sistemas proporcional e majoritário de representação, na linha do sistema adotado na Alemanha. Numa descrição sumária e simplificadora, o sistema funciona como exposto a seguir. Metade da Câmara dos Deputados é composta por parlamentares eleitos em distritos e a outra metade por candidatos eleitos pelo voto partidário. O eleitor, assim, tem dois votos: (i) um voto direto em um candidato no distrito (pelo sistema majoritário, 
em que o mais votado obtém a vaga); e (ii) outro voto em uma lista apresentada pelo partido (pelo sistema proporcional, em que o partido obtém o número de vagas correspondente à sua votação). Com o primeiro voto, elegem-se os representantes do distrito. Os Estados são subdivididos em distritos correspondentes ao número de cadeiras a serem preenchidas. Ilustrativamente: se o Estado tiver 10 milhões de eleitores e forem 20 as vagas a serem preenchidas pelo voto distrital, formam-se 20 distritos de 500 mil eleitores. Cada partido lança um candidato por distrito. À semelhança do que ocorre na eleição para Prefeito de Municípios com menos de 200 mil eleitores e Senador, o mais votado obtém a vaga, em um único turno. Há diversas vantagens na dimensão distrital do modelo: a) o barateamento da eleição, pois o candidato faz campanha para um número muito menor de eleitores, em espaço geográfico reduzido; e b) o aumento da representatividade democrática, pois o eleitor sabe quem representa o seu distrito na Câmara. Quando o representante candidatar-se à reeleição, o eleitor poderá verificar o desempenho do parlamentar ao longo do mandato e saber se deseja ou não reelegê-lo. Com o segundo voto, o eleitor escolhe o partido de sua preferência. A fórmula tradicional consiste em os partidos apresentarem uma lista fechada e pré-ordenada de candidatos (que, idealmente, deveria ser formada em eleições primárias internas ou a partir de outros procedimentos democráticos). Para evitar uma eventual rejeição à ideia de lista fechada e mitigar a possível ausência de democracia interna na formação da lista, pode-se considerar a formação da chamada lista semi-flexível, em que o eleitor teria a opção de dar o voto ou na legenda completa ou em um integrante da lista partidária. Se qualquer candidato, votado de forma avulsa, alcançar o quociente partidário com votos pessoais, ganhará o assento, independentemente da posição em que se encontre na lista. A dimensão partidária do modelo também possui múltiplas vantagens: a) evita a "paroquialização" das eleições (afasta-se o risco de cada parlamentar cuidar apenas dos interesses do seu distrito); b) assegura a representação proporcional das minorias políticas; c) permite a inclusão na lista de quadros técnicos qualificados (economistas, juristas, médicos, jornalistas, líderes comunitários ou sindicais), que ordinariamente não se disporiam a participar de uma campanha eleitoral, mas que poderiam elevar a qualidade do debate público; e d) fortalece o caráter unitário e de representação dos partidos políticos. 
Com efeito, a adoção de ampla reforma na sistemática eleitoral, para enfrentamento global das distorções antes mencionadas, na linha da proposta transcrita acima, parece ser mais eficaz do que a adoção de medidas pontuais, como a cláusula de votação nominal mínima, instituída pela minirreforma eleitoral de 2015, que acabam por descaracterizar aos poucos o sistema eleitoral proporcional, gerando novas distorções.

\section{Conclusão}

O sistema proporcional, qualquer que seja a subespécie adotada, possui como caraterística marcante a atribuição de papel destacado aos partidos políticos, enquanto representantes das diferentes correntes ideológicas em vigor em uma determinada sociedade, sendo a eles atribuídos os mandatos eletivos, por meio dos quocientes eleitoral e partidário, que, em um segundo momento, são distribuídos entre seus respectivos candidatos, de acordo com a votação obtida por cada um deles (ou de acordo com a ordem previamente estabelecida pela agremiação, caso se trate de sistema de lista fechada). Por conta dessa característica, a performance coletiva dos candidatos filiados à agremiação é mais relevante do que a votação individualmente obtida por cada um deles, contrapondo-se, assim, ao sistema majoritário, em que o prestígio pessoal do candidato junto ao eleitorado é o fator determinante para obtenção do mandato eletivo.

Diante da necessidade de prestigiar o grupo, o sistema proporcional inevitavelmente terá de contar com algum tipo de fórmula de transferência de votos entre os candidatos de determinada agremiação, o que pode gerar distorções, tal como o fenômeno dos chamados candidatos "puxadores de votos" e "caroneiros".

Visando restringir a eleição de candidatos com baixa representatividade política beneficiados pela transferência de votos de candidatos de grande projeção, a minirreforma eleitoral de 2015 instituiu cláusula de votação nominal mínima, vedando a eleição de candidatos cuja votação não alcance $10 \%$ do quociente eleitoral.

A exigência de votação nominal mínima foi objeto de críticas de parte da doutrina eleitoral e teve sua constitucionalidade questionada perante o Supremo Tribunal Federal, que, em recente decisão, julgou tal exigência constitucional e um avanço na sistemática eleitoral brasileira, por corrigir uma das notórias distorções em nossa fórmula de eleição proporcional. 
Contudo, grande parte dos problemas e distorções em nosso sistema eleitoral apontados quando do julgamento da ADI 5920, como a transferência de votos para candidatos desconhecidos ou de corrente ideológica diversa daquela que o eleitor pretendia prestigiar com seu voto, são, em alguma medida, inerentes ao próprio sistema eleitoral proporcional e não serão definitivamente eliminadas pela cláusula de votação nominal mínima.

Além disso, a instituição de tal exigência, apesar de certamente contribuir para dificultar a eleição de candidatos de pouca expressão e experiência política, pode, em contrapartida, levar à sub-representação política dos eleitores que adotem o voto de legenda ou que destinem seu voto a candidato que obtenha votação individual superior ao quociente eleitoral e integre partido político em que nenhum outro integrante da lista atinja a votação individual mínima.

Destarte, é possível concluir que, embora não se possa considerar inconstitucional a exigência de votação nominal mínima trazida pela minirreforma eleitoral de 2015, tal modificação, instituída com o objetivo pontual de corrigir a distorção causada pelos "puxadores de voto", traz consigo outros efeitos nefastos e potencialmente prejudiciais à adequada representação política das diferentes correntes ideológicas e posições partidárias vigente em nossa democracia, a evidenciar a necessidade de reformas e aprimoramentos mais amplos em nosso sistema eleitoral.

Nesse contexto, a proposta recentemente apresentada pelo Grupo de Trabalho constituído pelo Tribunal Superior Eleitoral, coordenado pelo ministro Luís Roberto Barroso, que sugere a adoção do sistema distrital misto nas cidades com mais de 200 mil habitantes, surge como possível solução para aumentar a representatividade democrática dos parlamentos, além de possivelmente baratear as eleições e facilitar a governabilidade.

\section{Referências}

BOBBIO, N. et al. Dicionário de Política. 1991. Brasilia: Universidade de Brasilia. MENDES, G. F. Reforma Eleitoral: Perspectivas atuais. Estudos Eleitorais, Tribunal Superior Eleitoral, 2016. v. 11. n.3.

NICOLAU, J. Sistemas Eleitorais. São Paulo: Saraiva, 2004.

NICOLAU, J. O Sistema eleitoral brasileiro: uma introdução. Rio de Janeiro: Konrad-Adenauer, 2007. 
SILVA, L. V. A. Sistemas eleitorais: tipos, efeitos jurídico-políticos e aplicação ao caso brasileiro. São Paulo: Malheiros, 1999.

VILELA JUNIOR., J. M. B. M. A Constituição, o Sistema Eleitoral Proporcional e a Minirreforma Eleitoral de 2015, Estudos Eleitorais. Tribunal Superior Eleitoral, 2016. v. 11. n.3.

Henrique Kurscheidt - Graduado em Direito pela Pontifícia Universidade Católica do Paraná (2007). Especialização em Direito Processual Civil pelo Instituto de Direito Romeu Felipe Bacellar (2010) e em Filosofia e Teoria do Direito pela Pontifícia Universidade Católica de Minas Gerais (2019). Atuou como advogado, na área cível, entre 2007 e 2013. Atualmente é Juiz de Direito no Paraná e leciona no curso de pós-graduação em Direito Aplicado da Escola da Magistratura do Paraná, núcleo Ponta Grossa. 